\title{
IMPLEMENTASI KEBIJAKAN PENGELOLAAN DANA DESA DI DESA TUMBANG TARUSAN KECAMATAN TEWANG SANGALANG GARING KABUPATEN KATINGAN
}

\author{
Implementation of Village Fund Management Policies in Tumbang Tarusan Village, \\ Tewang Sangalang Garing District, Katingan Regency
}

\section{Ambar Ratmoko* \\ Yahya Anugrah}

Universitas Muhammadiyah

Palangkaraya, Palangka Raya, Central

Kalimantan, Indonesia

email:

ambar.ratmoko@umpalangkaraya.ac.id

\section{Kata Kunci: \\ Implementasi \\ Kebijakan \\ Pengelolaan \\ Dana Desa \\ Keywords: \\ Implementation \\ Policy \\ Management \\ Village Fund}

\section{Accepted}

June 2016

\section{Published}

Oktober 2016

\begin{abstract}
Abstrak
Tujuan penelitian ini adalah untuk mengetahui Implementasi Kebijakan Pengelolaan Dana Desa Di Desatumbang Tarusan Kecamatan Tewang Sangalang Garing Kabupaten Katingan. Penelitian ini menggunakan penelitian kualitatif. Sumber data terdiri dari sumber primer. Teknik untuk mengumpulkan data dengan observasi, wawancara, dan dokumentasi.
\end{abstract}

Hasil Penelitian Implementasi Kebijakan Pengelolaan Dana Desa Di Desatumbang Tarusan Kecamatan Tewang Sangalang Garing Kabupaten Katingan yaitu Berdasarkan hasil penelitian dan pembahasan tentang Implementasi Kebijakan Pengelolaan Dana Desa di Desa Tumbang Tarusan Kecamatan Tewang Sangalang Garing Kabupaten Katingan berdasarkan 4 indikator yaitu Komunikasi, Sumberdaya, Disposisi dan Struktur Birokrasi dapat disimpulkan bahwa Implementasi Kebijakan Dana Desa di Desa Tumbang Tarusan Kecamatan Tewang Sangalang Garing dikatakan belum berhasil. Hal ini dikarenakan dari 4 indikator pengukur keberhasilan Implementasi hanya satu indikator yang menunjukkan suatu keberhasilan yaitu semberdaya. Sementara Komunikasi, Disposisi, dan Struktur Birokrasi masih belum berjalan dengan baik.

\begin{abstract}
The purpose of this study was to determine the Implementation of Village Fund Management Policies in Desatumbang Tarusan, Tewang Sangalang Garing District, Katingan District. This study uses qualitative research. The data source consists of primary sources. Techniques for collecting data by observation, interviews, and documentation.

Research Results Implementation of Village Fund Management Policies in Desatumbang Tarusan, Tewang Sangalang Garing District, Katingan Regency, Based on the results of research and discussion on the Implementation of Village Fund Management Policies in Tumbang Tarusan Village, Tewang Sangalang Garing Subdistrict, Katingan District based on 4 indicators: Communication, Resources, Disposition and Bureaucratic Structure It can be concluded that the Implementation of Village Fund Policy in Tumbang Tarusan Village, Tewang District, Sangalang Garing, is said to have not been successful. This is because of the 4 indicators that measure the success of the implementation, only one indicator shows a success, that is, power. While Communication, Disposition, and Bureaucratic Structure are still not going well.
\end{abstract}

\section{PENDAHULUAN}

Dalam Undang - Undang Nomor 6 Tahun 2014 tentang Desa, segala hak dan kewenangan Pemerintahan Desa telah diatur dengan segala macam teknis administrasi dan lain sebagainya secara rapi dan struktural serta hak kewenagangan desa dalam anggaran yang diperlukan dalam mengurusi dapur pemerintahannya sendiri
Berbicara tentang Administrasi yang ada di Desa, yang dimaksud Pengelolaan Keuangan Desa adalah keseluruhan kegiatan yang meliputi perencanaan, penganggaran, penata-usahaan, pelaporan, pertanggung jawaban dan pengawasan keuangan desa, Perencanaan desa diawali dengan pendataan aset, potensi dan kekuatan desa. Data tersebut menjadi dasar perencanaan pembangunan enam tahun yang tertuang dalam Rencana Pembangunan Jangka Menengah Desa 
(RPJMDes) dan Rencana Kegiatan Pembangunan Desa (RKPDes).

Berdasarkan observasi peneliti dilapangan bahwa dalam menjalankan proses pengelolaan Dana Desa di Desa Tumbang Tarusan Kecamatan Tewang Sangalang Garing masih belum sesuai dengan aturan yang ada, Aparatur Desa yang masih belum paham dalam menjalankan prosedur pengelolaan Dana Desa, serta kurangnya partisipasi masyarakat dalam pengawasan Dana Desa.

Menurut teori George C. Edwards III (Subarsono, 2005:90-92), Implementasi kebijakan dipengaruhi oleh empat variabel, yakni :

I. Komunikasi

Keberhasilan implementasi kebijakan mensyaratkan agar implementator mengetahui apa yang harus dilakukan, apa yang menjadi tujuan dan sasaran kebijakan harus ditransmisikan kepada kelompok sasaran (target groub) sehingga akan mengurangi distorsi implementasi.

2. Sumber Daya

Walaupun isi kebijakan sudah dikomunikasikan secara jelas dan konsisten, tetapi apabila implementor kekurangan sumber daya untuk melaksanakan, implementasi tidak akan berjalan efektif. Sumber daya tersebut akan berwujud sumber daya manusia, yakni kompetensi implementor, dan sumber daya finansial.

3. Disposisi

Disposisi adalaah watak dan karakteristik yang dimiliki oleh implementator, seperti komitmen, kejujuran, dan sifat demokrasi. Apabila implementator memiliki disposisi yang baik, maka dia akan dapat menjalankan kebijakan dengan baik seperti apa yang diinginkan oleh pembuat kebijakan.

4. Struktur Birokrasi

Struktur organisasi yang bertugas mengimplementasikan kebijakan memiliki pengaruh yang signifikan terhadap implementasi kebijakan.
Struktur organisasi yang telah panjang akan cenderung melemahkan pengawasan dan menimbulkan red-tape, yakni prosedur birokrasi yang rumit dan kompleks.

\section{Pengelolaan Keuangan Desa}

Undang-Undang No 6 tahun 2014 tentang Desa merupakan instrumen baru yang dikeluarkan oleh pemerintah pada awal tahun 2014 yang diikuti dengan PP No 43 tahun 2014 tentang Peraturan Pelaksanaan UU No 6 tahun 2014 tentang Desa dan PP No 60 tahun 2014 tentang Dana Desa yang Bersumber dari APBN. Keuangan Desa dikelola berdasarkan praktikpraktik pemerintahan yang baik. Asas-asas Pengelolaan Keuangan Desa sebagaimana tertuang dalam Permendagri Nomor I I 3 Tahun 2014 yaitu transparan, akuntabel, partisipatif serta dilakukan dengan tertib dan disiplin anggaran.

\section{METODOLOGI}

Metode penelitian yang digunakan dalam penelitian ini adalah penelitian kualitiatif, karena peneliti ingin memahami fenomena tentang apa yang dialami oleh subjek penelitian secara holistik dan dengan cara deskripftif dalam bentuk kata - kata dan bahasa, pada suatu konteks khusus yang alamiah dengan memanfaatkan berbagai metode alamiah.

\section{HASIL DAN PEMBAHASAN}

Dalam melakukan komunikasi kepada masyarakat, Pemerintah desa Tumbang Tarusan belum melakukannya dengan baik hal ini disebabkan pemerintah tidak terlalu terbuka terkait adanya penerimaan dana desa yang ada.

Sumberdaya manusia yang dimiliki Pemerintah Desa Tumbang Tarusan belum cukup memadai dalam hal pengelolaan Dana Desa. Yang dirasakan menjadi kendala adalah kompetensi yang dimiliki aparatur desa dalam pengelolaan dana desa serta dalam pembuatan 
dokumen pelaporan dana tersebut masih belum memahami. Akibatnya pembuatan dokumen terbebani pada Sekretaris Desa saja.

Pada point dalam Struktur Birokrasi, peneliti menemukan dalam Pelaksanaan Kebijakan Dana Desa di desa Tumbang Tarusan memang sudah dikoordinasikan langsung dengan pihak Badan Pemberdayaan Masyarakat dan Pemerintah Desa tetapi tidak dilakukan secara berkesinambungan. Mereka menjalankan kebijakan Pengelolaan Dana desa walaupun mereka tidak memahami apa yang mereka jalankan apakah sesuai dengan tujuan dan target pembangunan. Dalam pengawasan kebijakan Pengelolaan Dana desa peneliti juga menemukan kelemahan dan rentan sekali dengan penyelewengan. Hal ini dikarenakan sumber daya manusia dari Badan tersebut masih kurang memadai untuk Pendamping Lokal Desa (PLD) yang bertugas di lapangan.

\section{KESIMPULAN}

Berdasarkan hasil penelitian dan pembahasan tentang Implementasi Kebijakan Pengelolaan Dana Desa di Desa Tumbang Tarusan Kecamatan Tewang Sangalang Garing Kabupaten Katingan berdasarkan 4 indikator yaitu Komunikasi, Sumberdaya, Disposisi dan Struktur Birokrasi dapat disimpulkan bahwa Implementasi Kebijakan Dana Desa di Desa Tumbang Tarusan Kecamatan Tewang Sangalang Garing dikatakan belum berhasil. Hal ini dikarenakan dari 4 indikator pengukur keberhasilan Implementasi hanya satu indikator yang menunjukkan suatu keberhasilan yaitu semberdaya. Sementara Komunikasi, Disposisi, dan Struktur Birokrasi masih belum berjalan dengan baik.

Sehingga, diharapkan aparat desa dapat meningkatkan komunikasi dengan masyarakat tentang Dana Desa melalui Sosialisai, pertemuan dengan tokoh masyarakat dan tokoh agama, rapat musyawarah, serta penyampaian berita penerimaan dana desa melalui pengumuman yang di sampaikan melalui papan pengumuman desa yang ada disetiap depan rumah Ketua RT / RW.

Kemudian, diharapkan Aparat Desa dapat mengelola program Dana Desa dan melibatkan masyarakat dalam perencanaan program serta menjalankannya dengan aturan yang ada dan program kegiatan yang terencana dengan baik. Dalam struktur birokrasi sebaiknya Pemerintah Desa Tumbang Tarusan Meningkatkan intensitas koordinasi dan komunikasi secara berkesinambungan dengan Kabupaten agar dalam pelaksanaan kegiatan terhindar dari kesalahan dalam pengelolaan Dana Desa.

\section{REFERENSI}

Agustino Leo. 20I4. Dasar Kebijakan Publik. Bandung:Alfabeta.

Anggara Sahya. 2012. Ilmu Administrasi Negara. Bandung:CV.Pustaka Setia.

Anonim. 2014. Sejarah Singkat Kota Palangka Raya. Diakses dari http// www.PalangkaRaya.go.id/ Statis-Sejarahsingkatkotapalangkaraya.html. Tanggal 17 April 2016.

Bodgan, Robert. 2005. Participant Observation in Organizational settings, syracuse. University press.

Lexy,J.M. 2014. Metode Penelitian Kualitatif edisi revisi. Bandung : PT Remaja Rosdakarya.

Pahlawan, R., \& Andrean, E. 2015. Implementasi Kebijakan Pengelolaan Pertamanan di Kota Palangka Raya Provinsi Kalimantan Tengah. Restorica: Jurnal IImiah Ilmu Administrasi Negara Dan Ilmu Komunikasi, I (2), I-6.

Peraturan Daerah Kota Palangka Raya Nomor 8 tahun 2011 Tentang Pencegahan dan Penanggulangan HIVIAIDS.

Sugiyono AG. 2015. Analisis Kebijakan Publik Konsep Teori dan Aplikasi. Yogyakarta :Pustaka Pelajar.

Sugiyono. 2007. Metode Penelitian Administrasi dilengkapi dengan Metode R\&D. Bandung: Alfabeta. 